\title{
Potencial fisiológico de sementes de girassol influenciado pelo umedecimento artificial
}

\author{
Physiological potential of sunflower seeds as by the artificial moistening
}

\author{
Ludmila Fonseca da Silva' Claudia Antonia Vieira Rossetto ${ }^{\text {II }}$
}

\section{RESUMO}

O objetivo do trabalho foi avaliar a qualidade fisiológica de sementes de girassol após a hidratação pelos métodos da atmosfera úmida e substrato úmido em temperaturas de 10 e $20^{\circ} \mathrm{C}$ visando a elevar o teor de água das sementes a 15, 20 e 25\%. A qualidade fisiológica inicial e após o umedecimento das sementes foi determinada por testes de germinação e vigor (primeira contagem da germinação, germinação a baixa temperatura, emergência e índice de velocidade de emergência de plântulas em areia, massa de matéria seca e comprimento de plântulas). O método do substrato úmido a $10^{\circ} \mathrm{C}$ visando a aumentar o teor de água a 15 e 20\% foi favorável em sementes de elevada qualidade, embora com redução do vigor das plântulas.

Palavras-chave: Helianthus annus L., embebição, germinação, vigor, teor de água.

\section{ABSTRACT}

The objective of this study was to evaluate the sunflower seeds physiological quality after hydration by the moist atmosphere and moist substrate methods at temperatures of 10 and $20^{\circ} \mathrm{C}$ aiming to the water content of seeds at 15,20 and $25 \%$. The initial physiological quality and after the wetting of the seeds was determined by testing germination and vigor (first count of germination, germination at low temperature, emergence speed index and seedling emergence in sand, dry weight and length of seedlings). The method of moist substrate at $10^{\circ} \mathrm{C}$ to increase the water content at 15 and $20 \%$ was positive for moistening the seeds of high quality, although it has been observed small decrease seedling vigor.

Key words: Helianthus annus L., imbibition, germination, vigor, moisture.

\section{INTRODUÇÃO}

Durante a fase inicial do processo de germinação das sementes, há a promoção da atividade de mecanismos de reparo das membranas, de ácidos nucleicos e de outras macromoléculas, cujas membranas se reorganizam restabelecendo a permeabilidade seletiva (MARCOS FILHO, 2005). A eficiência de reorganização dos componentes celulares depende da velocidade de hidratação, do tempo de exposição ao ambiente úmido, da temperatura e das características intrínsecas da semente, tais como, permeabilidade do tegumento, composição química, teor de água inicial e qualidade fisiológica (BECKERT \& SILVA, 2002). Na composição das sementes de girassol, os lipídios absorvem menor quantidade de água do que sementes com baixo conteúdo de óleo (BALESEVIC-TUBIC et al., 2005).

A velocidade de reorganização do sistema de membranas reflete o vigor das sementes (CARVALHO et al., 2009); assim, temperaturas baixas e embebição rápida de sementes secas favorecem as perdas no vigor (ZUCARELI et al., 2008), evento também conhecido como dano por embebição (COSTA et al., 2008b). Na semente seca, as membranas estão no estado de gel, sendo menos fluidas, o que não constitui barreira à lixiviação de constituintes celulares e, quando são hidratadas, se reorganizam, alterando para o estado mais fluído ou cristalino líquido (OLIVER et al., 1998).

IPrograma de Pós-graduação em Fitotecnia, Universidade Federal Rural do Rio de Janeiro (UFRRJ), Seropédica, RJ, Brasil.

IIDepartamento de Fitotecnia, Instituto de Agronomia, UFRRJ, 23890-000, Seropédica, RJ, Brasil. E-mail: cavrosse@ufrrj.br. Autor para correspondência. 
Caso haja rápida embebição das sementes, não haverá tempo para as membranas evitar a perda de grande quantidade de solutos celulares (COSTA et al., 2008a).

Nas pesquisas em tecnologia de sementes, podem ocorrer situações em que há necessidade de umedecer as sementes, como, por exemplo, no estudo de danos mecânicos, secagem e embalagem, na avaliação da qualidade das sementes, nos testes de condutividade elétrica (RODRIGUES et al., 2006), deterioração controlada (ZUCARELI et al., 2008), que requerem a uniformização do teor de água entre os lotes de sementes. Para a realização desse procedimento, existem vários métodos, a exemplo da atmosfera úmida e do substrato úmido, porém é importante que o processo de uniformização do teor de água não altere a qualidade fisiológica das sementes e venha a afetar a avaliação do vigor (ZUCARELI et al., 2011). Para COSTA et al. (2008a), os resultados são diferentes quando as sementes são umedecidas tanto em contato com o substrato úmido como em atmosfera úmida. Em soja, ROSSETTO et al. (1995) recomendaram o método da atmosfera úmida a $20^{\circ} \mathrm{C}$ e RODRIGUES et al. (2006) o método do substrato úmido a $25^{\circ} \mathrm{C}$.

O objetivo do presente trabalho foi o de avaliar a qualidade fisiológica das sementes de girassol após a elevação do teor de água por métodos da atmosfera úmida e do substrato úmido em duas temperaturas.

\section{MATERIAL E MÉTODOS}

O experimento foi conduzido com dois lotes de sementes (aquênios) de girassol (Helianthus annus L.) adquiridos da EMBRAPA Agropecuária Oeste, em julho de 2009, os quais permaneceram armazenados até o início dos testes (três meses) em câmara seca a $18^{\circ} \mathrm{C}$ e $45 \%$ de umidade relativa do ar. As sementes utilizadas foram as retidas na peneira $16 / 64$ ” (5,90mm), com massa média de mil sementes de 73,32g. O delineamento experimental adotado foi o inteiramente casualizado, com quatro tratamentos de umedecimento artificial (método do substrato úmido e da atmosfera úmida combinados a 10 e $20^{\circ} \mathrm{C}$ ), para cada teor de água (15, 20 e 25\%), em quatro repetições.

O teor de água antes e após o umedecimento foi determinado pelo método da estufa a $105^{\circ} \mathrm{C}$, durante 24 horas, conforme as Regras para Análise de Sementes (BRASIL, 2009). Foram empregadas quatro subamostras de 50 sementes inteiras e os dois lotes de sementes utilizados estavam inicialmente com 6,21 e $7,02 \%$ de umidade. A avaliação da qualidade inicial e após o umedecimento foi realizada por testes de germinação e vigor. O teste de germinação foi conduzido com quatro subamostras de 50 sementes, utilizando papel tipo germitest a $20-30^{\circ} \mathrm{C}$, com avaliações realizadas aos quatro e 10 dias da instalação (BRASIL, 2009); em conjunto, foi realizado o teste de primeira contagem (NAKAGAWA, 1999). Para avaliação da massa de matéria seca, as plântulas normais obtidas nesta primeira contagem da germinação foram separadas em hipocótilo e raiz e levadas para secar em estufa a $60 \pm 5^{\circ} \mathrm{C}$ até atingir massa constante (ZUCARELI et al., 2008) e, posteriormente, pesadas. A massa obtida foi dividida pelo número de plântulas normais componentes, expresso em mg plântula ${ }^{-1}$ (NAKAGAWA, 1999). O teste de germinação a baixa temperatura foi realizado com quatro subamostras de 50 sementes, a $10^{\circ} \mathrm{C}$, por sete dias na ausência de luz, cujas avaliações foram realizadas aos quatro dias após a instalação do teste, com base no procedimento descrito por BRAZ et al. (2008). O teste de emergência em areia foi instalado com quatro subamostras de 50 sementes acondicionadas em caixas plásticas, cujo substrato foi areia lavada e esterilizada em autoclave e as avaliações foram realizadas diariamente, durante 21 dias (NAKAGAWA, 1999).

Para o umedecimento artificial, as sementes foram submetidas aos métodos da atmosfera úmida e do substrato úmido (ROSSETTO et al., 1995), nas temperaturas de 10 e $20^{\circ} \mathrm{C}$ até a elevação do teor de água para 15, 20 e $25 \%$. A massa a ser atingida pelas amostras para elevar o teor de água aos níveis desejados foi calculada considerando a massa e os teores iniciais de água delas e, periodicamente, essa massa foi monitorada mediante pesagem em balança analítica.

No método da atmosfera úmida, 100 sementes foram colocadas em cima da tela metálica fixada no interior de caixas plásticas contendo $40 \mathrm{~mL}$ de água destilada; no método do substrato úmido, 100 sementes foram distribuídas entre duas camadas de seis folhas de papel umedecidas com água destilada em cima da tela metálica, fixadas no interior de caixas de plástico contendo 40mL de água destilada.

Os testes de Lilliefors e de Cochran e Bartlett foram realizados para avaliação da normalidade e homogeneidade e, em seguida os dados obtidos foram submetidos à análise de variância (ZIMMERMANN, 2004) para cada ensaio e as médias comparadas pelo teste de Tukey a 5\% de probabilidade.

\section{RESULTADO E DISCUSSÃO}

Na avaliação inicial (Tabela 1), a germinação das sementes dos dois lotes de girassol (1 e 2) estava acima do padrão de comercialização que, segundo 
Tabela 1 - Germinação (G), primeira contagem da germinação (PC), germinação à baixa temperatura (GF), emergência de plântulas em areia (Em), índice de velocidade de emergência de plântulas (IVE), massa seca de raízes (MR) e de hipocótilo (MH), bem como comprimento de raiz (CR), de hipocótilo (CH) e total (CT), obtidos de dois lotes de sementes de girassol.

\begin{tabular}{lccccccccccc}
\hline Lotes & G (\%) & PC (\%) & GF (\%) & Em (\%) & IVE & MR (g) & MH $(\mathrm{g})$ & CR (cm) & CH (cm) & CT (cm) \\
\hline 1 & 96 & 60 & 95 & 92 & 8,46 & 0,0190 & 0,075 & 4,35 & 3,97 & 8,32 \\
2 & 76 & 30 & 69 & 82 & 6,19 & 0,0087 & 0,0035 & 4,29 & 3,62 & 7,91 \\
\hline
\end{tabular}

BRASIL (2005), é de 75\%. No entanto, os valores de vigor das sementes do lote 1 foram superiores aos do lote 2, após a aplicação de diversos testes.

Quando foi realizado o umedecimento das sementes visando a atingir o teor de água de $15 \%$, foi constatado que houve, para as sementes do lote 1 , redução do vigor avaliado pela menor porcentagem de plântulas normais na primeira contagem da germinação, após a exposição dessas sementes ao método da atmosfera úmida a $10^{\circ} \mathrm{C}$ (Tabela 2). Este resultado provavelmente foi devido a este procedimento ter sido lento em função da menor disponibilidade da água no estado de vapor, que promove a menor velocidade de germinação, como constatado por VILLELA et al. (2003). Além disso, para ALPERT \& OLIVER (2002), se a embebição ocorrer de maneira mais lenta e em temperatura baixa, não permitindo a mudança do estado das membranas de gel para cristalino, pode ocorrer liberação de solutos durante a embebição e, consequentemente, menor vigor.

Tabela 2 - Germinação, primeira contagem da germinação, germinação à baixa temperatura, emergência de plântulas em areia, índice de velocidade de emergência de plântulas, massa seca de plântulas (raízes e hipocótilo) e comprimento de plântulas (raiz, hipocótilo e total), obtidos de dois lotes de sementes de girassol umedecidos a 15\%, pelos métodos da atmosfera úmida (AU) e do substrato úmido (SU) sob 10 e $20^{\circ} \mathrm{C}$.

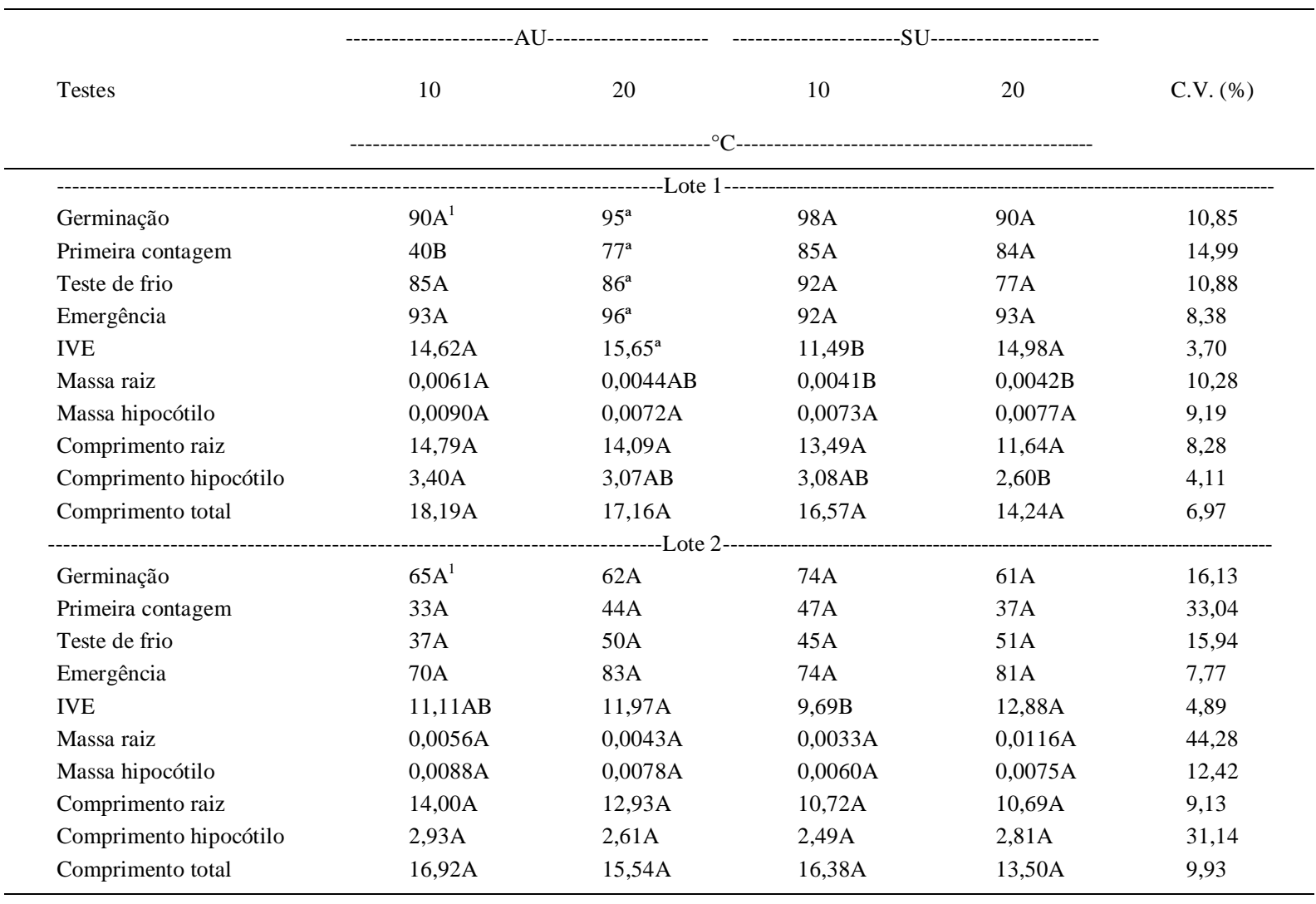

${ }^{1}$ Médias seguidas pelas mesmas letras, na linha, não diferem entre si pelo teste de Tukey a 5\%.

Ciência Rural, v.42, n.7, jul, 2012. 
Ao observar os demais dados dos lotes $1 \mathrm{e}$ 2 na tabela 2, foi constatado que os valores de massa de raízes e de hipocótilo, assim como de comprimento foram elevados após o umedecimento pelo método da atmosfera úmida a $10^{\circ} \mathrm{C}$, embora estes não tenham diferido estatisticamente dos obtidos após o umedecimento por outros métodos. Assim, esses resultados divergentes ao do teste de primeira contagem (Tabela 2) sugerem que a injúria de embebição pode não ter sido elevada, quando visou a atingir $15 \%$ de água, tendo em vista que não comprometeu o desenvolvimento das plântulas. Em soja, TOLEDO et al. (2010) observaram que as membranas tornaram-se estruturadas quando as sementes estavam com teor de água superior a $15 \%$, diminuindo a lixiviação de exsudatos e, consequentemente, favorecendo o vigor das sementes.

Também na tabela 2, quando foi comparada a porcentagem de germinação das sementes do lote 1 , após a exposição ao substrato úmido a $10^{\circ} \mathrm{C}$, com a da encontrada na avaliação inicial (Tabela 1), observou-se que houve aumento do valor. No entanto, em condições de campo, foi constatado menor índice de velocidade de emergência de plântulas provenientes dessas sementes, provavelmente devido à maior velocidade de hidratação das sementes em relação ao método da atmosfera úmida, levando ao reparo mais eficiente, principalmente quando associado à baixa temperatura de exposição, que não favorece a transição do estado das membranas, podendo propiciar a perda de vigor. Portanto, os danos provocados pela embebição rápida podem constituir em causa adicional à redução da emergência das plântulas, pois é a velocidade de reorganização do sistema de membranas que reflete no vigor das sementes (CARVALHO et al., 2009).

No entanto, esses resultados foram contraditórios em relação aos observados para sementes de soja (ROSSETTO et al., 1995), uma vez que obtiveram resultados favoráveis após a exposição das sementes ao método da atmosfera úmida a $20^{\circ} \mathrm{C}$, devido a menor velocidade de embebição em comparação à hidratação pelo método do substrato úmido a $10^{\circ} \mathrm{C}$. Assim, este efeito mais favorável da germinação das sementes de girassol após a hidratação pelo método da atmosfera úmida (Tabela 2) também pode ser devido, provavelmente, à maior porcentagem de óleo nas sementes de girassol do que nas de soja. Para BALESEVIC-TUBIC et al. (2005), quanto mais alto o conteúdo de óleo nas sementes menor é a absorção de água, sendo que outro aspecto ainda a ser considerado nesta explicação pode estar relacionado ao fato de que em girassol as sementes estão aderidas ao pericarpo (aquênio). Assim, além da dificuldade imposta pelo tegumento para a absorção de água pelas sementes (COSTA et al., 2008b), há a restrição proveniente do pericarpo, tornando o processo mais lento.

Também foi possível constatar que, quando foi utilizado o método do substrato úmido a $20^{\circ} \mathrm{C}$, as plântulas provenientes das sementes do lote 1 estavam com menor comprimento do hipocótilo, o que pode estar relacionado ao fato de a velocidade de embebição ter sido maior, prejudicando a eficiência de reparo das membranas; além disso, para CROWE et al. (1989), em temperaturas mais altas, as membranas das sementes se encontram no estado cristalino líquido e assim podem tolerar a absorção rápida de água.

Quando se realizou o umedecimento das sementes visando a atingir o teor de água de $20 \%$ (Tabela 3), foi observado que, para o lote 1 , a porcentagem de plântulas na primeira contagem foi a menor após a exposição das sementes ao método da atmosfera úmida a $10^{\circ} \mathrm{C}$, embora o valor não tenha diferido daquele após a exposição ao mesmo método a $20^{\circ} \mathrm{C}$. Tal resultado provavelmente pode estar relacionado à lenta velocidade de embebição promovida por este método, associada à baixa temperatura, como também constatado no ensaio, objetivando elevar o teor de água das sementes a 15\% (Tabela 2).

Para os lotes 1 e 2, foram constatados menores valores de porcentagem de emergência, bem como de massa seca de raízes e de hipocótilo das plântulas após o umedecimento, buscando atingir 20\% de água, pelo método da atmosfera úmida a $10^{\circ} \mathrm{C}$, embora este valor não tenha diferido estatisticamente de outro método (Tabela 3). Os resultados diferem do observado no ensaio, visando atingir 15\% de água (Tabela 2), podendo indicar que houve maior perda de vigor quando se objetivou atingir $20 \%$ de água do que para elevar a 15\% de água.

Também, pelos dados da tabela 3 , foi verificado que, para os dois lotes, quando foi comparada a germinação após a exposição ao substrato úmido a $10^{\circ} \mathrm{C}$ com a da avaliação inicial (Tabela 1 ), não houve alteração dos valores, enquanto o umedecimento pelos demais métodos promoveu redução da germinação. No entanto, ao comparar os quatro métodos, foi verificado menor valor de massa seca de raízes e de hipocótilo das plântulas provenientes de sementes umedecidas por este método, provavelmente, devido à maior velocidade de hidratação das sementes em relação ao método da atmosfera úmida, como comentado por ocasião da avaliação do ensaio, visando a aumentar o teor de água para 15\% (Tabela 2).

Quando foi realizado o umedecimento das sementes objetivando atingir 25\% de água (Tabela 4), 
Tabela 3 - Germinação, primeira contagem da germinação, germinação à baixa temperatura, emergência de plântulas em areia, índice de velocidade de emergência, massa seca de plântulas (raízes e hipocótilo) e comprimento de plântulas (raiz, hipocótilo e total), obtidos dos lotes de sementes de girassol umedecidos a 20\%, pelos métodos da atmosfera úmida (AU) e do substrato úmido (SU) sob 10 e $20^{\circ} \mathrm{C}$.

\begin{tabular}{|c|c|c|c|c|c|}
\hline Testes & 10 & 20 & 10 & 20 & C.V. (\%) \\
\hline \multicolumn{6}{|c|}{--------------------------------------------------------------------------------Lote 1------------------------------------------------------------------------------- } \\
\hline Germinação & $87 A^{1}$ & $91 \mathrm{~A}$ & $96 \mathrm{~A}$ & $94 \mathrm{~A}$ & 7,63 \\
\hline Primeira contagem & $61 B$ & $82 \mathrm{AB}$ & $94 \mathrm{~A}$ & $85 \mathrm{~A}$ & 11,84 \\
\hline Teste de frio & $78 \mathrm{~A}$ & $72 \mathrm{~A}$ & 96A & $73 \mathrm{~A}$ & 16,53 \\
\hline Emergência & $86 \mathrm{~B}$ & $97 \mathrm{~A}$ & $97 \mathrm{~A}$ & $98 \mathrm{~A}$ & 6,70 \\
\hline IVE & $15,44 \mathrm{~A}$ & $11,64 \mathrm{~A}$ & $12,28 \mathrm{~A}$ & $11,95 \mathrm{~A}$ & 1,69 \\
\hline Massa raiz & 0,0034B & $0,0062 \mathrm{~A}$ & $0,0035 \mathrm{~B}$ & $0,0062 \mathrm{~A}$ & 6,36 \\
\hline Massa hipocótilo & $0,0074 \mathrm{~B}$ & $0,0090 \mathrm{AB}$ & $0,0077 \mathrm{AB}$ & 0,0093A & 5,32 \\
\hline Comprimento raiz & $13,46 \mathrm{~A}$ & $15,25 \mathrm{~A}$ & $10,56 \mathrm{~A}$ & $15,19 \mathrm{~A}$ & 10,49 \\
\hline Comprimento hipocótilo & $3,23 \mathrm{~A}$ & $3,21 \mathrm{~A}$ & $2,54 \mathrm{~A}$ & $3,45 \mathrm{~A}$ & 10,34 \\
\hline Comprimento total & $16,69 \mathrm{~A}$ & $18,46 \mathrm{~A}$ & $13,10 \mathrm{~A}$ & $18,64 \mathrm{~A}$ & 10,42 \\
\hline Germinação & $68 \mathrm{~A}^{1}$ & 56A & $76 \mathrm{~A}$ & $59 \mathrm{~A}$ & 30,00 \\
\hline Primeira contagem & $50 \mathrm{~A}$ & $46 \mathrm{~A}$ & $71 \mathrm{~A}$ & $37 \mathrm{~A}$ & 30,91 \\
\hline Teste de frio & $64 \mathrm{~A}$ & $47 \mathrm{AB}$ & $65 \mathrm{~A}$ & $28 B$ & 12,61 \\
\hline Emergência & $61 B$ & $81 \mathrm{~A}$ & $68 \mathrm{~B}$ & $82 \mathrm{~A}$ & 6,35 \\
\hline IVE & $9,98 \mathrm{~A}$ & $8,99 \mathrm{~A}$ & $9,01 \mathrm{~A}$ & $9,58 \mathrm{~A}$ & 8,77 \\
\hline Massa raiz & $0,0041 \mathrm{BC}$ & $0,0046 \mathrm{AB}$ & $0,0028 \mathrm{C}$ & $0,0062 \mathrm{~A}$ & 10,26 \\
\hline Massa hipocótilo & $0,0063 B$ & $0,0072 \mathrm{AB}$ & $0,0064 \mathrm{~B}$ & $0,0088 \mathrm{~A}$ & 6,98 \\
\hline Comprimento raiz & $14,66 \mathrm{~A}$ & $10,67 \mathrm{~B}$ & $9,28 \mathrm{~B}$ & $14,66 \mathrm{~A}$ & 5,56 \\
\hline Comprimento hipocótilo & $3,08 \mathrm{~A}$ & $2,23 \mathrm{~B}$ & $2,29 B$ & $2,74 \mathrm{AB}$ & 5,64 \\
\hline Comprimento total & $17,74 \mathrm{~A}$ & $12,90 \mathrm{~B}$ & $11,56 \mathrm{~B}$ & $17,40 \mathrm{~A}$ & 4,88 \\
\hline
\end{tabular}

${ }^{1}$ Médias seguidas pelas mesmas letras, na linha, não diferem entre si pelo teste de Tukey a 5\%.

foi constatado, para o lote 1 , que a germinação das sementes expostas aos quatro métodos de umedecimento foi superior ou igual à encontrada na avaliação inicial (Tabela 1), sugerindo que pode ter ocorrido reparo metabólico para atingir este conteúdo de água. No entanto, para o lote 2, de menor qualidade fisiológica (Tabela 1), a germinação das sementes expostas apenas ao método do substrato umedecido a $20^{\circ} \mathrm{C}$ se manteve em relação à inicial, o que pode estar relacionado ao maior nível de deterioração das sementes do lote 2 em relação às do lote 1 . De acordo com ROSSETTO et al. (1995), o alto grau de desorganização das membranas possivelmente dificulta a reorganização e o reparo metabólico, pois segundo ZUCARELI et al. (2008) os lotes de sementes com baixo potencial fisiológico não são adequados para estudos de métodos de hidratação. Além disso, à medida que foram avaliadas as sementes do lote 2 , foi constatado maior teor de água no final do período de embebição (dados não apresentados), ainda que o tempo previsto para atingir este valor pretendido tenha sido o mesmo. Resultados semelhantes foram observados por ROSSETTO et al. (1995) para sementes de soja.

Para o lote 1, na avaliação do vigor pelo teste de germinação à baixa temperatura, foram verificados os menores valores após o umedecimento, visando a atingir $25 \%$ pelo método da atmosfera úmida e do substrato úmido a $20^{\circ} \mathrm{C}$ (Tabela 4). Para MARCOS FILHO (2005), à medida que a semente se hidrata, esta se torna particularmente sensível às baixas temperaturas.

Também na tabela 4 foi verificado, para os lotes 1 e 2, menor comprimento do hipocótilo das plântulas provenientes de sementes umedecidas pelo método do substrato úmido a $10^{\circ} \mathrm{C}$, tendência verificada principalmente para as sementes do lote 2 , objetivando atingir 15 e $20 \%$ (Tabelas 2 e 3). 
Tabela 4 - Germinação, primeira contagem da germinação, germinação à baixa temperatura, emergência de plântulas em areia, índice de velocidade de emergência de plântulas, massa seca de plântulas (raízes e hipocótilo) e comprimento de plântulas (raiz, hipocótilo e total), obtidos de dois lotes de sementes de girassol umedecidos a $25 \%$, pelos métodos da atmosfera úmida (AU) e do substrato úmido (SU) sob 10 e $20^{\circ} \mathrm{C}$.

\begin{tabular}{|c|c|c|c|c|c|}
\hline \multirow[b]{2}{*}{ Testes } & \multicolumn{2}{|c|}{ 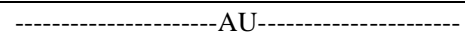 } & 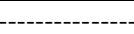 & ------------- & \multirow[b]{2}{*}{ C.V. (\%) } \\
\hline & 10 & 20 & 10 & 20 & \\
\hline \multicolumn{6}{|c|}{ 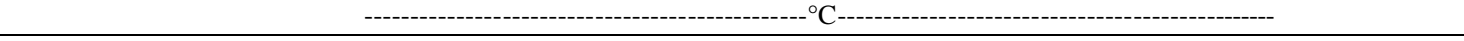 } \\
\hline & 1 & 094 & 094 & 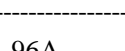 & 527 \\
\hline Germinação & $99 A^{1}$ & $98 \mathrm{~A}$ & 99A & 96A & 5,37 \\
\hline Primeira contagem & $80 \mathrm{~A}$ & $85 \mathrm{~A}$ & $88 \mathrm{~A}$ & $84 \mathrm{~A}$ & 9,87 \\
\hline Teste de frio & $66 \mathrm{~B}$ & $65 B$ & $65 \mathrm{~B}$ & $97 \mathrm{~A}$ & 12,32 \\
\hline Emergência & $96 \mathrm{~A}$ & $99 \mathrm{~A}$ & $97 \mathrm{~A}$ & $95 \mathrm{~A}$ & 7,96 \\
\hline IVE & $13,30 \mathrm{~B}$ & $12,11 \mathrm{BC}$ & $11,72 \mathrm{C}$ & $15,73 \mathrm{~A}$ & 2,92 \\
\hline Massa raiz & $0,0021 \mathrm{~B}$ & $0,0050 \mathrm{~A}$ & $0,0015 B$ & $0,0058 \mathrm{~A}$ & 16,89 \\
\hline Massa hipocótilo & $0,0045 B$ & 0,0092A & 0,0038B & 0,0030B & 15,32 \\
\hline Comprimento raiz & $7,61 \mathrm{AB}$ & $9,81 \mathrm{~A}$ & $5,51 \mathrm{~B}$ & $9,75 \mathrm{~A}$ & 10,72 \\
\hline Comprimento hipocótilo & $1,99 \mathrm{AB}$ & $2,75 \mathrm{~A}$ & $1,65 \mathrm{~B}$ & $2,75 \mathrm{~A}$ & 9,70 \\
\hline Comprimento total & $9,60 \mathrm{AB}$ & $12,55 \mathrm{~A}$ & $7,16 \mathrm{~B}$ & $12,50 \mathrm{~A}$ & 10,42 \\
\hline Germinação & $68 \mathrm{AB}^{1}$ & $61 \mathrm{~B}$ & $71 \mathrm{AB}$ & $76 \mathrm{~A}$ & 8,01 \\
\hline Primeira contagem & $28 \mathrm{~A}$ & $36 \mathrm{~A}$ & $52 \mathrm{~A}$ & $42 \mathrm{~A}$ & 19,35 \\
\hline Teste de frio & $19 \mathrm{~A}$ & $24 \mathrm{~A}$ & $35 \mathrm{~A}$ & $54 \mathrm{~A}$ & 43,05 \\
\hline Emergência & $75 \mathrm{~A}$ & $73 \mathrm{~A}$ & $78 \mathrm{~A}$ & $83 \mathrm{~A}$ & 6,63 \\
\hline IVE & $10,15 B$ & $8,50 \mathrm{~B}$ & $8,82 \mathrm{~B}$ & $12,73 \mathrm{~A}$ & 4,42 \\
\hline Massa raiz & $0,0027 \mathrm{AB}$ & $0,0038 \mathrm{AB}$ & 0,0018B & $0,0049 \mathrm{~A}$ & 20,33 \\
\hline Massa hipocótilo & $0,0057 \mathrm{AB}$ & $0,0086 \mathrm{~A}$ & $0,0040 \mathrm{BC}$ & $0,0021 \mathrm{C}$ & 17,16 \\
\hline Comprimento raiz & $9,03 \mathrm{~A}$ & $8,41 \mathrm{~A}$ & $5,15 \mathrm{~A}$ & $7,70 \mathrm{~A}$ & 16,52 \\
\hline Comprimento hipocótilo & $2,21 \mathrm{~A}$ & $2,82 \mathrm{~A}$ & $1,27 \mathrm{~B}$ & $2,25 \mathrm{~A}$ & 11,51 \\
\hline Comprimento total & $11,23 \mathrm{~A}$ & $11,23 \mathrm{~A}$ & $6,43 \mathrm{~A}$ & $9,95 \mathrm{~A}$ & 15,18 \\
\hline
\end{tabular}

${ }^{1}$ Médias seguidas pelas mesmas letras, na linha, não diferem entre si pelo teste de Tukey a 5\%.

\section{CONCLUSÃO}

O método do substrato úmido a $10^{\circ} \mathrm{C}$ visando a aumentar o teor de água a 15 e $20 \%$ é favorável em sementes de elevada qualidade, embora com redução do vigor das plântulas.

\section{AGRADECIMENTOS}

À Coordenação de Aperfeiçoamento de Pessoal de Nível Superior (CAPES) e ao Conselho Nacional de Desenvolvimento Científico e Tecnológico (CNPq), pela concessão das bolsas de pesquisa.

\section{REFERÊNCIAS}

ALPERT, P.; OLIVER, M.J. Drying without dying. In: BLACK, M.; PRITCHARD, H.W. (Ed.). Desiccations and survival in plants: drying without dying. Wallingford: CABI Publishing, 2002. p.4-43. Disponível em: <http://books.google.com.br/ books?>. Acesso em: 14 jun. 2011.

BALESEVIC-TUBIC, S. et al. Influence of natural aging on the dynamics of water absorption by sunflower seed. Seed Science and Technology, v.33, n.1, p.255-258, 2005. Disponível em:
$<$ http://www.ingentaconnect.com/content/ista/sst/2005/ 00000033/00000001/art00027>. Acesso em: 14 jun. 2011.

BECKERT, O.P.; SILVA, W.R. Tecnologia de sementes: o uso da hidratação para estimar o desempenho de sementes de soja. Bragantia, v.61, n.1, p.61-69, 2002. Disponível em: <http:/ /www.scielo.br/scielo.php?script=sci_arttext\&pid=S0006$87052002000100010 \& \operatorname{lng}=p t \& n r m=i$ iso \& $\ln g=p t>$. Acesso em: 02 set. 2011. doi: 10.1590/S0006-87052002000100009.

BRASIL. Instrução Normativa no25, de 16 de Dezembro de 2005. Diário Oficial da República Federativa do Brasil, Poder Executivo, DF, 2005. Disponível em: <http:// www.cidasc.sc.gov.br/html/legislacao/>. Acesso em: 14 jun. 2011.

BRASIL. Ministério da Agricultura, Pecuária e Abastecimento. Regras para análise de sementes. Brasília: Secretaria de Defesa Agropecuária/MAPA/ACS, 2009. 395p.

BRAZ, M.R.S. et al. Testes de envelhecimento acelerado e deterioração controlada na avaliação do vigor de aquênios de girassol. Ciência Rural, v.38, n.7, p.1857-1863, 2008. Disponível em: $<$ http://www.scielo.br/scielo.php?script=sci_arttext\&pid=S0103$84782008000700009 \& \operatorname{lng}=p t \& n r m=i s o \& t \operatorname{lng}=p t>$. Acesso em: 14 jun. 2011. doi: 10.1590/S0103-84782008000700009. 
CARVALHO, L.F. et al. Influência da temperatura de embebição da semente de soja no teste de condutividade elétrica para avaliação da qualidade fisiológica. Revista Brasileira de Sementes, v.31, n.1, p.9-17, 2009. Disponível em: <http:// www.scielo.br/scielo.php?script=sci_arttext\&pid=S0101 $31222009000100001 \& \operatorname{lng}=p t \& n r m=i s o \& t \operatorname{lng}=p t>$. Acesso em: 02 set. 2011. doi: 10.1590/S0101-31222009000100001.

COSTA, C.J. et al. Pré-hidratação de sementes de ervilha e sua interferência na avaliação do potencial fisiológico. Revista Brasileira de Sementes, v.30, n.1, p.198-207, 2008a. Disponível em: <http://www.scielo.br/pdf/rbs/v30n1/ a25v30n1.pdf $>$. Acesso em: 02 set. 2011. doi: 10.1590/S010131222008000100025 .

COSTA, C.J. et al. Expressão de isoenzimas após a pré-hidratação de sementes de ervilha. Revista Brasileira de Sementes, v.30, n.3, p.130-138, 2008b. Disponível em: <http:// www.scielo.br/scielo.php?script=sci_arttext\&pid=S0101 $31222008000300017 \& \operatorname{lng}=\mathrm{pt} \& \mathrm{nrm}=\mathrm{iso} \& \mathrm{tlng}=\mathrm{pt}>$. Acesso em: 02 set. 2011. doi: 10.1590/S0101-31222008000300017.

CROWE, J.H. et al. Membrane phase transitions are responsible for imbibitional damage in dry pollen. Proceedings of the National Academy of Sciences of the United States of America, v.86, n.2, p.520-523, 1989. Disponível em: <http:/ /www.ncbi.nlm.nih.gov/pmc/articles/PMC286503>. Acesso em 14 jun. 2011.

MARCOS FILHO, J. Fisiologia de sementes de plantas cultivadas. Piracicaba: FEALQ, 2005. 495p.

NAKAGAWA, J. Testes de vigor baseados na avaliação das plântulas. In: KRZYZANOWSKI, F.C. et al. Vigor de sementes: conceitos e testes. Londrina: ABRATES, 1999. Cap.2, p.1-24.

OLIVER, A.E. et al. Methods for dehydration-tolerance: depression of the phase transition temperature in dry membranes and carbohydrate vitrification. Seed Science Research, v.8, n.2, p.211-221, 1998. Disponível em: <http:// journals.cambridge.org/action/displayAbstrac>. Acesso em: 14 jun. 2011. doi: 10.1017/S0960258500004128.
RODRIGUES, M.B.C. et al. Pré-hidratação em sementes de soja e eficiência do teste de condutividade elétrica. Revista Brasileira de Sementes, v.28, n.2, p.168-181, 2006. Disponível em: <http:/ /www.scielo.br/scielo.php?script=sci_arttext\&pid=S0101$31222006000200023 \& \operatorname{lng}=\mathrm{pt} \& \mathrm{nrm}=\mathrm{iso} \& \mathrm{t} \operatorname{lng}=\mathrm{pt}>$. Acesso em 14 jun. 2011. doi: 10.1590/S0101-31222006000200023.

ROSSETTO, C.A.V. et al. Metodologias de ajuste do grau de umidade e comportamento das sementes de soja no teste de germinação. Revista Brasileira de Sementes, v.17, n.2, p.171-178, 1995. Acesso em: 14 jun. 2011.

TOLEDO, M.Z. et al. Imbibition damage in soybean seeds as affected by initial moisture content, cultivar and production location. Seed Science and Technology, v.38, n.2, p.399408, 2010. Disponível em: <http://www.ingentaconnect.com/ content/ista/sst/2010/00000038/00000002/art00013>. Acesso em: 02 set. 2011

VILLELA, F.A. et al. Estado energético da água na semente de milho no processo de germinação. Revista Brasileira de Sementes, v.25, n.1, p.95-100, 2003. Disponível em: <http:/ /www.scielo.br/scielo.php?script=sci_arttext\&pid=S0101$31222003000100015 \& \operatorname{lng}=p t \& n r m=i s o \& t \operatorname{lng}=p t>$. Acesso em: 02 set. 2011. doi: 10.1590/S0101-31222003000100015.

ZIMMERMANN, F.J.P. Estatística aplicada à pesquisa agrícola. Santo Antônio de Goiás: Embrapa Arroz e Feijão. 2004. 402p

ZUCARELI, C. et al. Potencial fisiológico de sementes de milho hidratadas pelo método do substrato de papel toalha. Revista Brasileira de Sementes, v.30, n.3, p.122-129, 2008. Disponível em: <http://www.scielo.br/scielo.php?script=sci_arttext\&pid=S0101$31222008000300016 \& \operatorname{lng}=p t \& n r m=i s o \& t \operatorname{lng}=p t>$. Acesso em: 14 jun. 2011. doi: 10.1590/S0101-31222008000300016.

ZUCARELI, C. et al. Métodos e temperaturas de hidratação na qualidade fisiológica de sementes de milho. Revista Ciência Agronômica, v.42, n.3, p.684-692, 2011. Disponível em: <http:/ /www.scielo.br/scielo.php?script=sci_arttext\&pid=S1806$66902011000300015 \& \operatorname{lng}=p t \& n r m=i s o \& t l n g=p t>$. Acesso em: 12 jan. 2012. doi: 10.1590/S1806-66902011000300015. 